\title{
ULTRASTRUCTURAL PROPERTIES OF THE ADRENAL GLANDS DURING THE ACUTE HYPOXIA
}

\author{
PhD, Assistant Professor Yagubova Samira Mammadhasan \\ Azerbaijan, Baku Azerbaijan Medical University, \\ Department of Pathological Anatomy
}

DOI: https://doi.org/10.31435/rsglobal_ws/31102019/6719

\section{ARTICLE INFO}

Received: 21 August 2019

Accepted: 18 October 2019

Published: 31 October 2019

\section{KEYWORDS}

adrenocorticocytes, hypobaric hypoxia,

adrenal cortex

adrenal medulla.

\begin{abstract}
The goal of the study was to study the morphofunctional properties of ultrastructural changes in the cellular and extracellular structures of the adrenal glands during hypobaric hypoxia. The materials of the study were 30 male white rats weighing 180-200 grams. Thus, the results of the conducted studies showed that morphofunctional changes under the effects of acute hypoxia, which develop in different zones of the adrenal cortex, also change the histofunctional state of the adrenal medulla. Morphometric indicators of the adrenal parenchyma increase from the 5 th day of hypoxia and are characterized by the increased blood supply to the adrenal glands, which occurs both by the dilatation of capillaries and by an increase in their density.
\end{abstract}

Citation: Yagubova Samira Mammadhasan. (2019) Ultrastructural Properties of the Adrenal Glands During the Acute Hypoxia. World Science. 10(50), Vol.1. doi: 10.31435/rsglobal_ws/31102019/6719

Copyright: (C) 2019 Yagubova Samira Mammadhasan. This is an open-access article distributed under the terms of the Creative Commons Attribution License (CC BY). The use, distribution or reproduction in other forums is permitted, provided the original author(s) or licensor are credited and that the original publication in this journal is cited, in accordance with accepted academic practice. No use, distribution or reproduction is permitted which does not comply with these terms.

Introduction. Hypoxia or oxygen deficiency is a typical pathological process that occurs when the oxygen supply of tissues or its use in biological oxidation processes in the body is disrupted [1]. Hypoxia is not only considered a pathological phenomenon. A person constantly feels the effect of oxygen deficiency or physiological hypoxia in his daily life. Unlike pathological hypoxia, changes in organs and tissues during physiologic hypoxia are of a short-term and reversible [2,3].

Currently, in connection with the development of a science of hypoxia, knowledge on the application of acute and chronic hypoxia has been expanded not only for the pathogenesis of hypoxia but also for their prevention and correction, as well as specific training for professional activities [4]. Chronic hypoxia or short-term effects of hypoxia are widely used in increasing the possibility of adaptation of the organism, psychophysiological states, respiratory system, cardiovascular system, mainly in the function of organs of the endocrine system, as well as in the treatment of many diseases and pathological processes [5,6].

Endocrine system organs, especially the adrenal glands, hormones synthesized and secreted by their cells, are important in the formation of compensatory-adaptive processes in the body due to adverse environmental factors, including hypoxia. The analysis of the literature reveals a disagreement between the authors. A group of authors notes the strengthening of the functional activity of the adrenal glands in the adaptation process of the organism to hypoxia of different origins (changes in the size of adrenocytes), and other authors note the weakening of the functional activity of the glands $[7,8]$.

From this point of view, the need for pathogenetic justification of new mechanisms for the development of renal adaptation mechanisms at the molecular, cellular, tissue, organ and system levels, as well as metabolic and functional disorders in these glands during hypoxia remains actual.

The goal of the study was to study the morphofunctional properties of ultrastructural changes in the cellular and extracellular structures of the adrenal glands during acute hypobaric hypoxia.

Materials and methods. The materials of the study were 30 male white rats weighing 180200 grams, divided into 3 groups. Animals (10) included in the control group were not intervened; 
respectively acute hypoxia model was established in the II and III experimental groups, each of which had 10 experimental animals. The animals included in group II were kept in the specially hypobaric chamber with an atmospheric pressure of 2000-3000 meters above sea level and temperature of 19200C 5 times a week for 2 hours, rats of III group were kept in the specially hypobaric chamber with an atmospheric pressure of 2000-3000 meters above sea level every 2 hours. To absorb the CO2 formed in the hypobaric chamber, grains of natron lime $(\mathrm{Ca}(\mathrm{OH}) 281 \%+\mathrm{NaOH} 3,4 \%+\mathrm{H} 2 \mathrm{O} 15,6 \%)$ were used. All experiments were conducted at the time of the day, which is considered the lightest time. Animals removed from the barocamera were kept under control in standard vivarium conditions.

All painful procedures were carried out under a superficial effusion drug, and the killing of animals was carried out with 2-2.5\% thiopental-sodium solution injected into the peritoneal cavity at $100 \mathrm{mg} / \mathrm{kg}$ and anesthetized. Animals separated in all three groups were decapitated at different times of the experiment - on the 2nd and 5th day of the experiment, rats included in the control group - on the 2nd, 5th day. The adrenal glands were completely cut and preparations were taken for histological and electron microscopic examination.

After macroscopic evaluation, the preparations were fixed in fragments and post-fixed for two hours. 2\% solution of glutaraldehyde and 2\% paraformaldehyde prepared in phosphate buffer $(\mathrm{pH}=7,4)$ were used for fixation, and $1 \%$ solution of osmic acid prepared in the same buffer was used for postfixation. After postfixation preparations kept at $50^{\circ}, 70^{\circ}, 80^{\circ}, 90^{\circ}$ ethyl alcohol solutions for 30 minutes, and at $96^{\circ}$ and $100^{\circ}$ of the same solutions for 1 hour. The dehydrated preparations are placed in special forms made by Araldite-Epon and spur to form blocks. From these blocks were made half$(1-2 \mu \mathrm{m})$ and ultrathin $(70-100 \mathrm{~nm})$ sections in ultratom LCB - III, Leica EM UC7. The sections are stained with hematoxylin-eosin and PAS, covered with encrusted glass through Canadian balm. Microscopic examination was performed under x8, x20 and x40 magnification [9]. Microphotography of the structural elements of the thyroid and adrenal glands was performed by a digital camera of the microscope "Olympus BX-41", and morphometric parameters were calculated by Wilcoxon test (paired samples) Statistica 10 (StatSoft. Inc.).

Research on animals was conducted in the Department of Pharmacology and Experimental Surgery of the Scientific Research Center and Electron Microscopy Laboratory of AMU on the basis of ethical rules specified in Protocol No. 31 of the ethic rules Commission and bioethics committee under the Ministry of the Health of the Republic of Azerbaijan on 21.04.2008.

Results and discussion. The adrenal gland is an endocrine organ and consists of two parts the adrenal cortex and the adrenal medulla, which have different origins, structure, and shape. The adrenal cortex is $70-80 \%$ of the volume of the organ, synthesizes corticosteroid hormones that affect the immune system, the course of inflammatory processes and various types of metabolism. The adrenal medulla secretes catecholamines, which affect the activity of the cardiovascular and nervous system, glandular epithelium, mainly carbohydrate metabolism and thermogenesis.

Macroscopically in rats included in the control group, the adrenal glands are clearly visible on the upper poles of the kidneys in the retroperitoneal tissue space, under the diaphragm. During the visual examination of histological preparations taken from animals, the adrenal cortex and adrenal medulla, surrounded by a thick capsule consisting of dense connective tissue, are separated from each other by clear boundaries. The connective tissue capsule is made by a small number of glucosaminoglycans and other organic substances.

According to electron microscopic studies, in animals included in the control group, the nuclei of adrenocorticocytes of the glomerular zone of the adrenal gland are rounded and located mainly in the center of the cell, and the nuclei are outside the center. The membrane of the nucleus and the nucleolus are clearly visible, made by granular components. In the cytoplasm of adrenocorticocytes of the glomerular zone, mainly under the capsule and on the central part a large number of lysosomes and a small amount lysosomes with smooth edges on the border with the fascicular zone are identified. The edges of the mitochondria of the cells of the glomerular zone are denticular, the cristae have a lamellar structure. (fig.1, marked with a red arrow).

The number of ribosomes and liposomes in the cytoplasm of adrenocytes of the fascicular zone is low (fig.1, marked with a white arrow). They are unevenly distributed in the cytoplasm. A small number of lysosomes are mainly located around the Golgi complex. It should be noted that the number of lysosomes in the deep layers of the fascicular zone and near the reticular zone is very small (fig.2, marked with a white arrow). Spongiocytes of the fascicular zone has large mitochondria with curved surfaces compared with the 
cells of the glomerular zone, and vesicular cristae with vacuoles appear in the transverse section, and the vacuoles are associated with the inner membrane of the mitochondria.

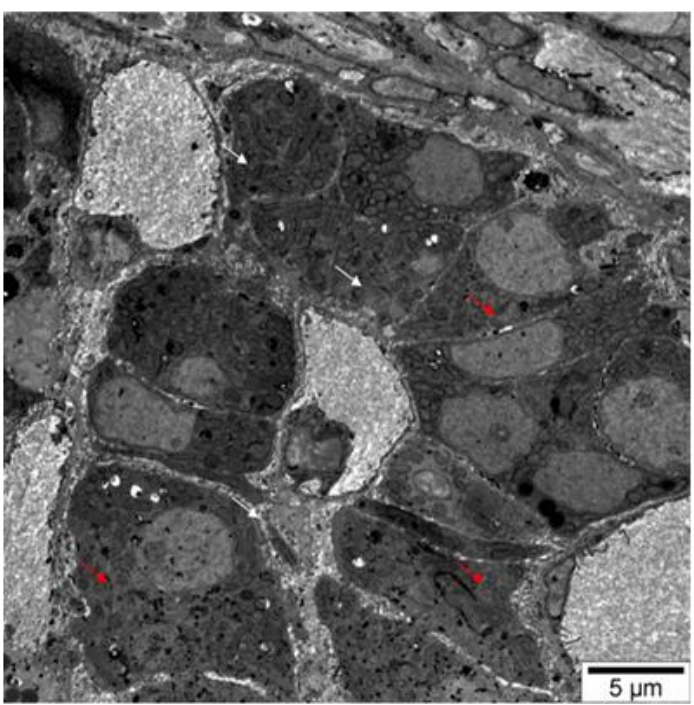

Fig. 1. Electron microscopic images of normal structures involved in the formation of the adrenal gland. TEM. The explanation is given in the text. Dye: uranium acetate and plumbum citrate. Scale: $5 \mu \mathrm{m}$.

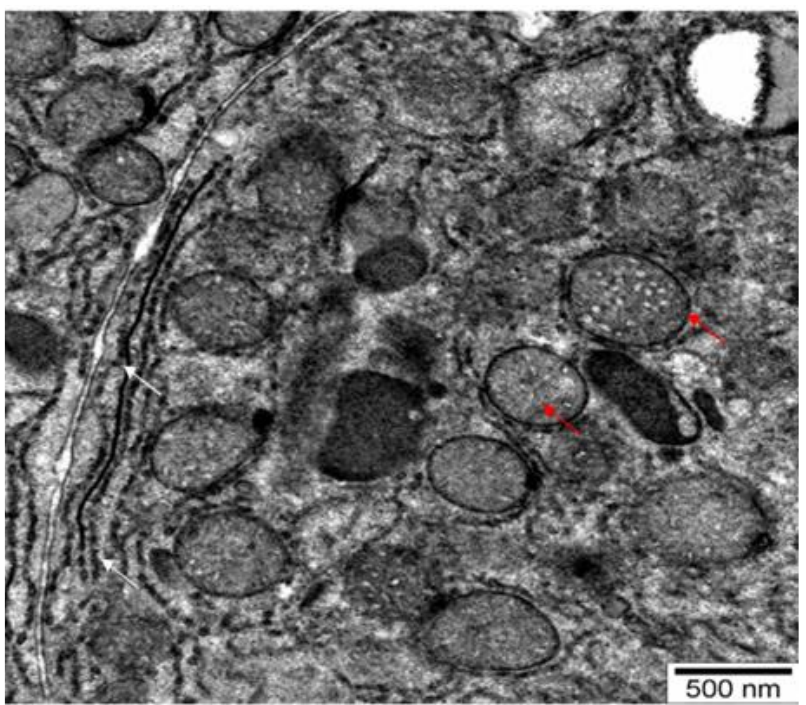

Fig. 2. Electron microscopic images of normal structures involved in the formation of the adrenal gland. TEM. The explanation is given in the text. Dye: uranium acetate and plumbum citrate. Scale: $500 \mathrm{~mm}$.

Adrenocorticocytes of the reticular zone are characterized by significant polymorphism, unlike adrenocorticocytes of the fascicular and glomerular zone. In their cytoplasm, numerous mitochondria, their nuclei are located, mainly, circular and excentric, have condensed chromatin. In the adrenocytes of the reticular zone, the number of liposomes is less, contours are mostly smooth (fig.3, marked with a red arrow).

The large polygonal nuclei of the adrenal medulla appear in the center of the cytoplasm. Organelles, especially mitochondria and lysosomes are clearly noticeable in the vacuolized cytoplasm (fig.3, marked with a red arrow).

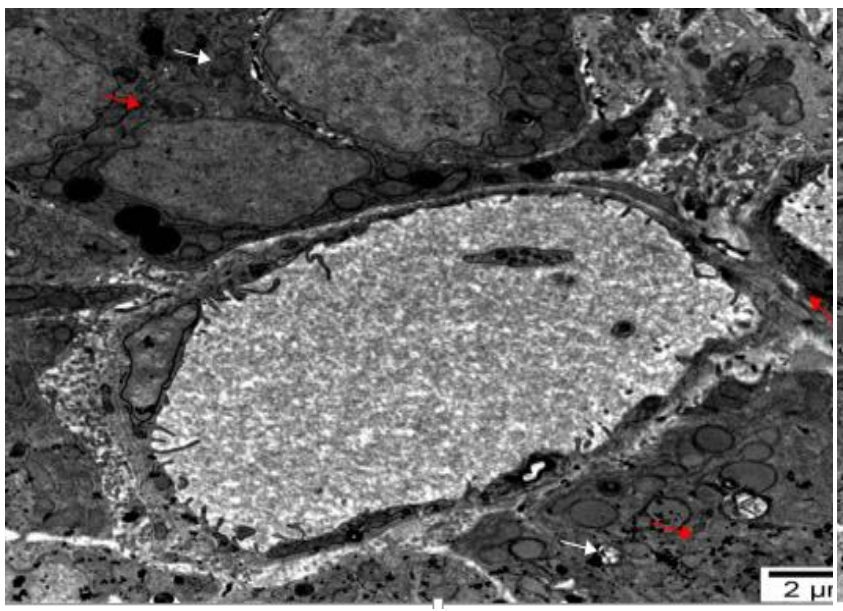

Fig. 3. Electron microscopic images of normal structures involved in the formation of the adrenal gland. TEM. The explanation is given in the text. Dye: uranium acetate and plumbum citrate. Scale: $2 \mu \mathrm{m}$.

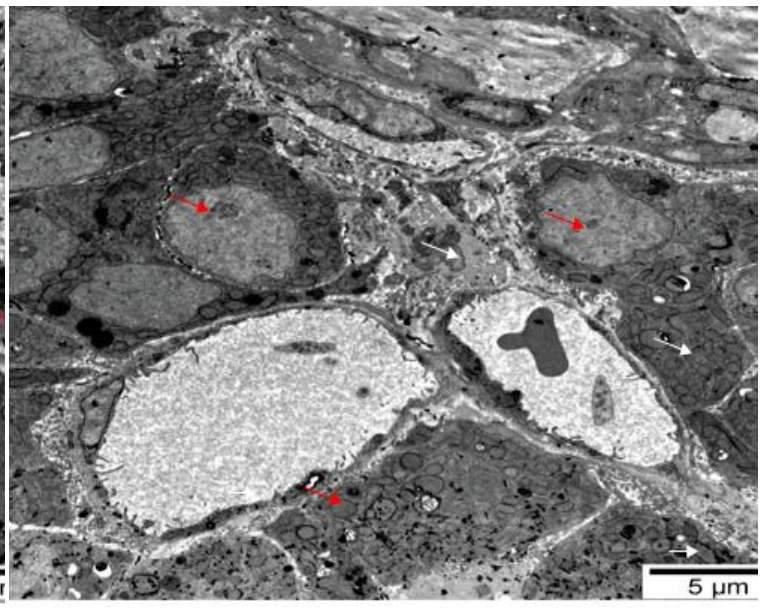

Fig. 4. Electron microscopic images of normal structures involved in the formation of the adrenal gland. TEM. The explanation is given in the text. Dye: uranium acetate and plumbum citrate. Scale: $500 \mathrm{~mm}$.

On the 2nd day of the experiment, weak alterative and destructive changes under the effect of hypobaric hypoxia are detected in the histotopography of the adrenal glands of animals. The quantitative indicators obtained as a result of the study also did not undergo any different changes compared to the control group (tab.1). 
Table 1. Morphometric indicators of the nuclei of the adrenal gland $(\mathrm{M} \pm \mathrm{m}),(\min -\mathrm{max})$ in norm and in acute hypoxia

\begin{tabular}{|c|c|c|c|c|c|c|c|c|c|c|c|c|}
\hline & \multicolumn{3}{|c|}{$\begin{array}{c}\text { Glomerular zone } \\
(\operatorname{Max} \pm \min )\end{array}$} & \multicolumn{3}{|c|}{$\begin{array}{l}\text { Fascicular zone } \\
(\operatorname{Max} \pm \min )\end{array}$} & \multicolumn{3}{|c|}{$\begin{array}{c}\text { Reticular zone } \\
(\operatorname{Max} \pm \min )\end{array}$} & \multicolumn{3}{|c|}{ Adrenal medulla (Max \pm min) } \\
\hline & \multirow[t]{2}{*}{$\mathrm{N}$} & \multicolumn{2}{|c|}{$\begin{array}{c}\text { Days of } \\
\text { experiment }\end{array}$} & \multirow[t]{2}{*}{$\mathrm{N}$} & \multicolumn{2}{|c|}{$\begin{array}{c}\text { Deys of } \\
\text { experiment }\end{array}$} & \multirow[t]{2}{*}{$\mathrm{N}$} & \multicolumn{2}{|c|}{$\begin{array}{c}\text { Days of } \\
\text { experiment }\end{array}$} & \multirow[t]{2}{*}{$\mathrm{N}$} & \multicolumn{2}{|c|}{ Days of experiment } \\
\hline & & $\begin{array}{l}2^{\text {nd }} \\
\text { day }\end{array}$ & $\begin{array}{l}5^{\text {th }} \\
\text { day }\end{array}$ & & $2^{\text {nd }}$ day & $5^{\text {th }}$ day & & $\begin{array}{l}2^{\text {nd }} \\
\text { day }\end{array}$ & $\begin{array}{l}5^{\text {th }} \\
\text { day }\end{array}$ & & $2^{\text {nd }}$ day & $5^{\text {th }}$ day \\
\hline $\begin{array}{l}\text { Diameter } \\
\mathrm{M} \pm \mathrm{m}\end{array}$ & $\begin{array}{c}4,44 \\
\pm 0,27\end{array}$ & $\begin{array}{c}4,63 \\
\pm 0,26\end{array}$ & $\begin{array}{c}4,87 \\
\pm 0,26\end{array}$ & $\begin{array}{c}5,55 \\
\pm 0,20\end{array}$ & $\begin{array}{c}5,74 \\
\pm 0,19\end{array}$ & \begin{tabular}{|c|}
6,03 \\
$\pm 0,21$
\end{tabular} & $\begin{array}{c}4,45 \pm \\
0,17\end{array}$ & $\begin{array}{c}4,63 \pm \\
0,17\end{array}$ & $\begin{array}{c}4,87 \pm \\
0,16\end{array}$ & $\begin{array}{c}5,47 \pm \\
0,19\end{array}$ & $\begin{array}{c}5,66 \pm \\
0,19 * *\end{array}$ & $\begin{array}{l}5,94 \pm \\
0,22 * *\end{array}$ \\
\hline Min-max & $\begin{array}{c}2,66- \\
5,82\end{array}$ & $\begin{array}{c}2,87- \\
5,97\end{array}$ & $\begin{array}{l}3,01- \\
6,14\end{array}$ & $\begin{array}{l}4,62- \\
6,35\end{array}$ & $\begin{array}{l}4,88- \\
6,57\end{array}$ & $\begin{array}{l}5,15- \\
7,01\end{array}$ & $\begin{array}{l}3,77- \\
5,26\end{array}$ & $\begin{array}{l}3,97- \\
5,47\end{array}$ & $\begin{array}{c}4,19- \\
5,75\end{array}$ & $\begin{array}{c}4,66- \\
6,35\end{array}$ & $\begin{array}{l}4,87- \\
6,57\end{array}$ & $\begin{array}{l}5,01- \\
7,01\end{array}$ \\
\hline $\begin{array}{c}\text { Square } \\
\mathrm{M} \pm \mathrm{m}\end{array}$ & $\begin{array}{c}46,0 \pm \\
3,83\end{array}$ & $\begin{array}{c}47,9 \pm \\
3,87 \\
* *\end{array}$ & $\begin{array}{c}50,1 \pm \\
3,92 \\
* *\end{array}$ & $\begin{array}{c}34,2 \pm \\
1,87\end{array}$ & $\begin{array}{c}36,1 \pm \\
1,84 \\
* *\end{array}$ & $\begin{array}{c}38,3 \pm \\
1,80 \\
* *\end{array}$ & $\begin{array}{c}23,9 \pm \\
2,16\end{array}$ & $\begin{array}{c}25,6 \pm \\
2,18 \\
* *\end{array}$ & $\begin{array}{c}27,6 \pm \\
2,28 \\
* *\end{array}$ & $\begin{array}{c}30,9 \pm \\
1,47\end{array}$ & $\begin{array}{c}32,8 \pm \\
1,38 \\
* *\end{array}$ & $\begin{array}{c}35,0 \pm \\
1,32 \\
* *\end{array}$ \\
\hline Min-max & $\begin{array}{l}33,53- \\
68,45\end{array}$ & $\begin{array}{l}34,67- \\
70,54\end{array}$ & $\begin{array}{l}36,95- \\
73,45\end{array}$ & $\begin{array}{l}23,47- \\
41,64\end{array}$ & $\begin{array}{c}26,58- \\
43,78\end{array}$ & $\begin{array}{r}28,76- \\
45,69\end{array}$ & $\begin{array}{l}15,47- \\
36,43\end{array}$ & $\begin{array}{l}17,64- \\
38,52\end{array}$ & $\begin{array}{l}18,76- \\
40,13\end{array}$ & $\begin{array}{l}23,47- \\
37,63\end{array}$ & $\begin{array}{l}26,58- \\
39,17\end{array}$ & $\begin{array}{l}28,76- \\
41,46\end{array}$ \\
\hline
\end{tabular}

*Note: N-control group; $\mathrm{n}$-number of animals; $\mathrm{M} \pm \mathrm{m}$ : M-average indicator of variation, $\mathrm{m}$ standard error, $* *-\mathrm{p}<0,01$

The relative growth of the volume of the adrenal gland of experimental animals, relaxing the capsule, pale-yellowish in color and partial fragility of the consistency is visible with a naked eye. It is possible to visually distinguish the contours of the cortical and medullary substances of the gland.

Electron-microscopic studies conducted on the 2nd day of the experiment showed that, unlike microscopic examination of glandular cells, structural changes on the ultrastructural level as a result of hypoxia are more clearly noticeable (fig.4, marked with a white arrow). Thus, the cytoplasm of the adrenocytes of the adrenal cortex are edematous, the nuclei are deformed. The double-nucleolar nucleus has coincided. In the cytoplasm, there are derivatives of the cell boundary - the basal membrane, it is possible to see a violation of the completeness of the basal membrane even in some cells of the adrenal medulla.

The condensed chromatin is diffusely distributed in the cytoplasm, especially in the cytoplasm of the glomerular zone, and the destruction of chromatin in the cells of the reticular zone is noted (fig.4, marked with a red arrow).

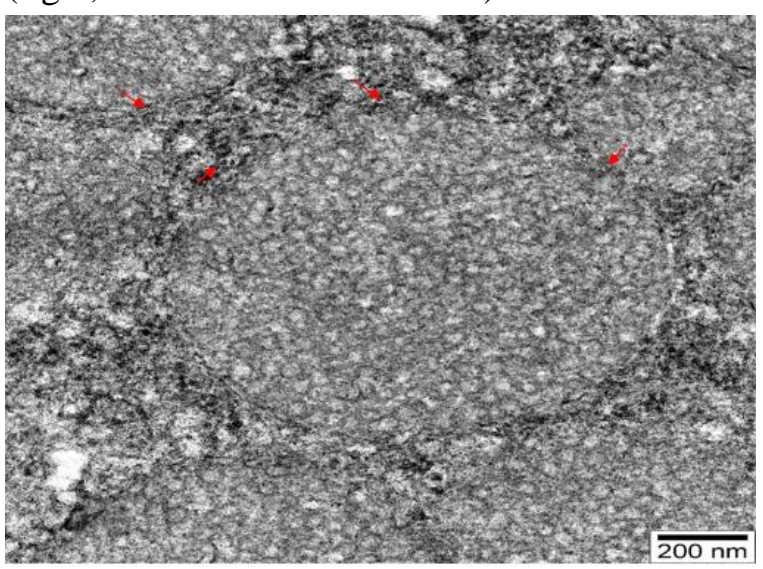

Fig. 5. 2nd day of hypoxia. Electron microscopic images of structures of the adrenal gland. TEM.

The explanation is given in the text. Dye: uranium acetate and plumbum citrate. Scale: $200 \mathrm{~nm}$.

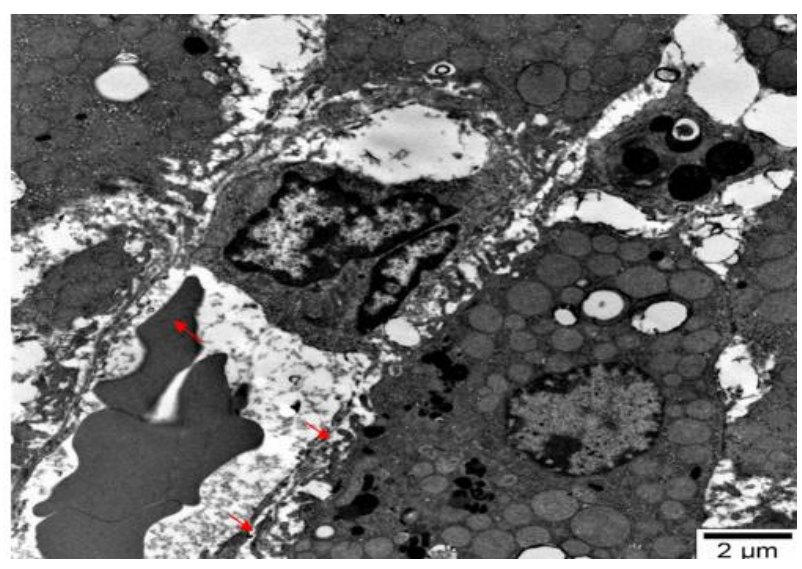

Fig. 6. 2nd day of hypoxia. Electron microscopic images of structures of the adrenal gland. TEM. The explanation is given in the text. Dye: uranium acetate and plumbum citrate. Scale: $2 \mu \mathrm{m}$.

More mitochondria than intracellular organelles have undergone dystrophic changes, in particular, mitochondria of the adrenal cortex is edematous, mainly in elongated form, have cristae with unclear contours. Edema of adrenocytes simultaneously affected the function of organelles, causing their vacuolization and destruction. The endoplasmic reticulum and Golgi complex appear weak. In spongiocytes, secretory granules are small and rarely occur (fig.4, marked with a white arrow). 
The cytoplasm of the adrenal medulla is edematous, the nucleus is swollen, the chromatine is pale, the fenestrae of the endothelial cells of the capillary covering the adrenocytes are clearly visible. Destructive changes in the organelles of adrenocytes in the focal areas of the adrenal medulla are observed. Thus, mitochondria are hypertrophied, lysosomes are scattered in the cytoplasm (fig.5, marked with a white arrow). During the study of ultrathin sections, gross ultrastructural changes in connective tissue and plasmolemma are not detected (fig.6, marked with a white arrow).

On the 5th day of the experiment, due to hypoxia the acute irreversible pathomorphological changes that occur as a result of a violation of tissue nutrition in the adrenocytes of the adrenal gland. As a result of hypoxia, many tissues, cells, organelles of the gland completely lost their structural properties and have been subjected to acute destruction. Also in the statistical indicators of the experiment, sharp changes characteristic of the effect of hypoxia are noted (tab.1).

Macroscopically, the adrenal gland is yellowish gray, sharply increased in volume, softened and became brittle. The growth of its volume caused the release of connective tissue fibers of the capsule covering the gland, the appearance of grayish-pink in the transverse section reflects the damage to the tissue inside the gland. The release of connective tissue fibers is manifested by the breakdown of trabeculae directed from the capsule into the gland.

5 days after the creation of the hypoxia model, in ultrathin sections taken from the adrenal gland tissue of animals, complete destruction of cells inherent in the adrenal gland tissue, damage to cell organelles, coagulation of cytoplasmic proteins were observed. The capsule of the gland is released, dispersed in some parts. The cytoplasm of adrenocorticocytes is acute edematous, its nuclei are gloomy, adjacent to the cytolemma, the basal membrane is loosened and a folding is formed on it, the nucleoli are not noticeable, mitochondria are discharged, lysis of cristae (fig.7, marked with a red arrow), secondary dystrophic changes secretory granules and of lipids have occurred. The membrane of the nucleus is fibrous, rarely invagination of the membrane occurs in the adrenocytes of the adrenal cortex (fig.7, marked with a white arrow). Under the influence of hypoxia, karyopyknosis of the nuclei of the cells of the adrenal cortex and fading of nuclear chromatin, destruction of the reticular zone, as well as vacuolization of lysosomes are detected. In cytoplasm, the ultrastructure of the lipid droplets of adrenocorticocytes was changed, most of them were isolated, some of them were located apically under plasmolemma. Acute edema of adrenocytes caused the destruction of the endoplasmic reticulum and Golgi complex (fig.8, marked with a white and red arrow).

Dystrophic changes in the cytoplasm of the adrenal medulla are also noted. In the ultrathin sections, numerous fat deposits and edematous nucleus, destroyed nuclear chromatin in the cytoplasm are detected. Acute swelling and smoothening of mitochondrial cristae, loss of endoplasmic reticulum and lysosomes, ignoring glycogen granules are associated with fat dystrophy of intracellular organelles, the intracellular space is expanded (fig.9, marked with a red arrow).

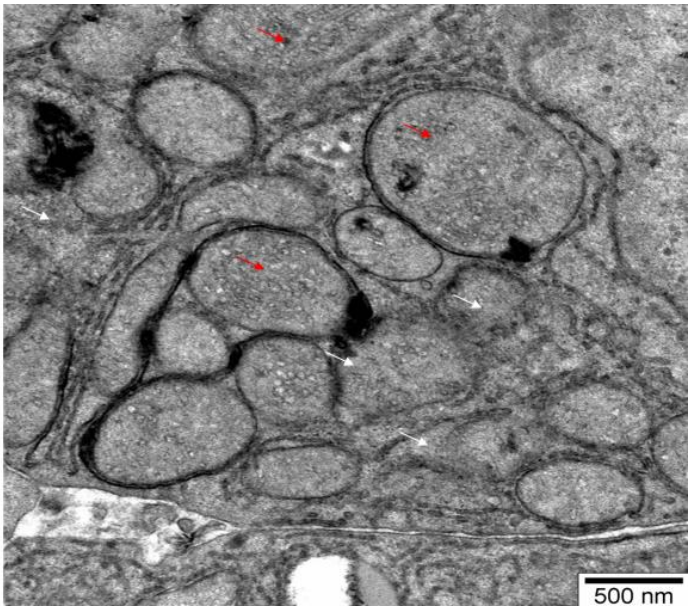

Fig. 7. 5th day of hypoxia. Electron microscopic images of structures of the adrenal gland. TEM. The explanation is given in the text. Dye: uranium acetate and plumbum citrate. Scale: $500 \mathrm{~nm}$.

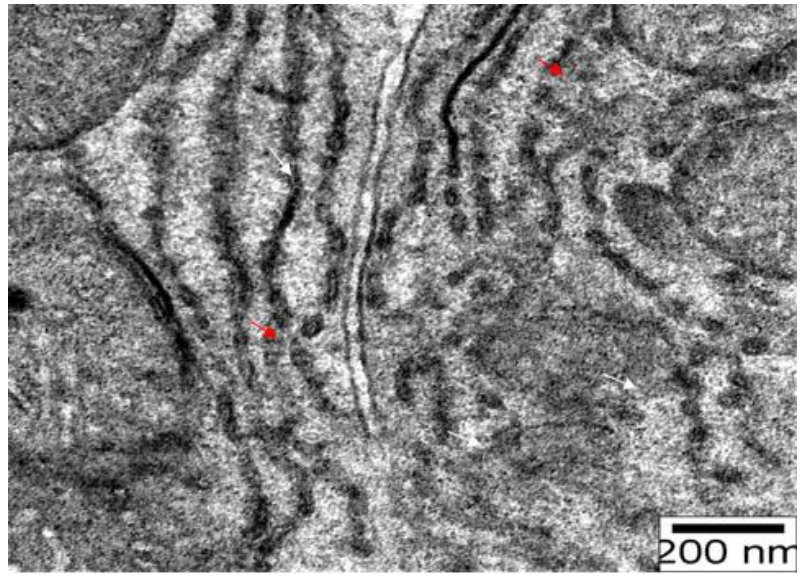

Fig. 8. 5th day of hypoxia. Electron microscopic images of structures of the adrenal gland. TEM. The explanation is given in the text. Dye: uranium acetate and plumbum citrate. Scale: $200 \mathrm{~nm}$. 
Acute edema of the interstitial area, a violation of the shape of fibrous structures, noticeable changes in the internal endothelial and external basal membrane of the walls of the capillaries are explained by a violation of tissue nutrition under the influence of hypoxia (fig.9, marked with a white arrow).

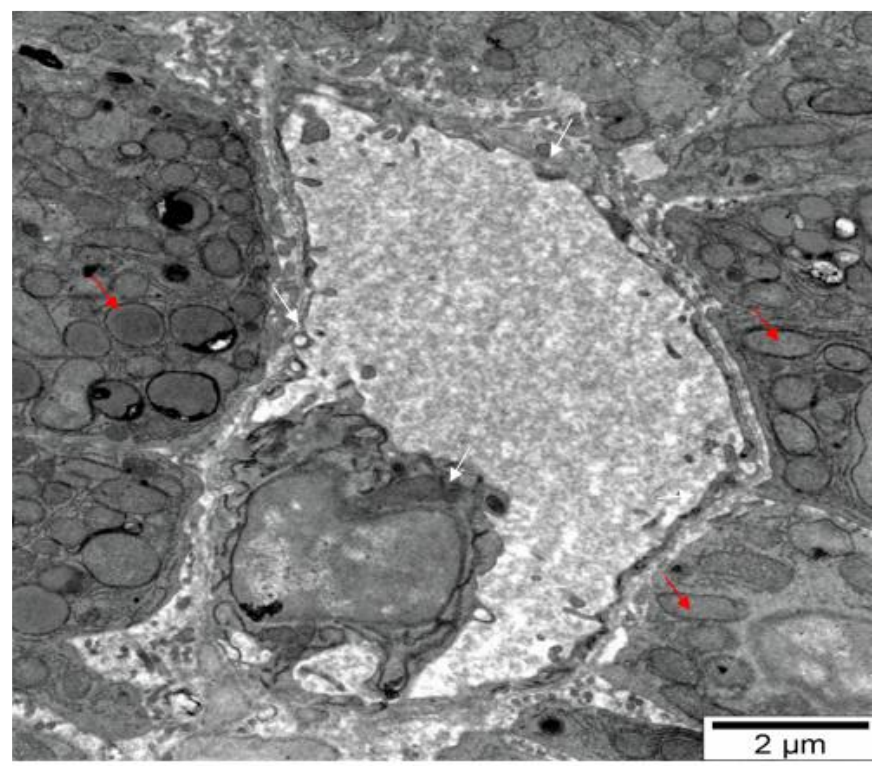

Fig. 9. 5th day of hypoxia. Electron microscopic images of structures of the adrenal gland. TEM. The explanation is given in the text. Dye: uranium acetate and plumbum citrate. Scale: $2 \mu \mathrm{m}$.

Thus, the results of the conducted studies showed that morphofunctional changes under the effects of acute hypoxia, which develop in different zones of the adrenal cortex, also change the histofunctional state of the adrenal medulla. Thus, the effect of hypoxia leads to significant dystrophic changes in the adrenocorticocytes of the adrenal gland, as well as to a change in the interaction of glomerular, fascicular and reticular zones, an increase in the activity of the adrenal medulla. Increased adrenocortical activity during the initial effect of hypoxia provokes the synthesis and secretion of adrenocortotropic hormone. Morphometric indicators of the adrenal parenchyma increase from the 5th day of hypoxia and are characterized by the increased blood supply to the adrenal glands, which occurs both by the dilatation of capillaries and by an increase in their density.

\section{REFERENCES}

1. Zarechnova N.N., Slynko E.N. Influence of mountain hypoxia on endocrine system organs at the insufficiency of adrenal and pancreatic hormones // Bulletin of new medical technologies, electronic journal, 2018, № 4, p.3-10

2. Zerkalova Y.F. Morphological and functional changes of some endocrine glands during hypoxia of different genesis // Avtoref.cand.dis..., Ulyanovsk, 2004, 23p.

3. Kalyuzhnaya L.I. Endocrine mechanisms of adaptation to the high altitude [Text]: in the book: Hypoxia. Adaptation, pathogenesis, clinic // Under the editorship of J.L.Shevchenko / Kalyuzhnaya, L.I., Tararak T.I., Kalyuzhny I.T.- SPb: LLC "ELBI-SPb", 2000, pp.235-265.

4. Sadykova G.S., Dzhunusova G.S. Functional features of endocrine systems in the inhabitants of the highlands // International journal of applied and fundamental research, 2016, № 4-5, pp.943-947.

5. Mukhametov A.I. Morphofunctional characteristic of adrenal glands of rabbits in the conditions of stress and its correction // Author's abstract. Cand. Dis..., Orenburg, 2015, 24p.

6. Woods DR., Davison A., Stacey M., Smith C., Hooper T., Neely D., Turner S., Peaston R., Mellor A. The cortisol response to hypobaric hypoxia at rest and post-exercise. Hormone and Metabolic Research 2012, 44, pp.302-305.

7. Mvon Wolff, C.T. Nakas, M.Tobler, T.M.Merz, M.P.Hilty, J.D.Veldhuis, A. R.Huber and J.Pichler Hefti. Adrenal, thyroid and gonadal axes are affected at high altitudes. Endocrine connection, 2018, Volume 7: Issue 10, pp.1081-189.

8. Erik R.Swenson, Peter Bartsch, High Altitude/Human Adaptation to Hypoxia, Springer, New York, 2014, $495 \mathrm{pp}$.

9. Weekly B.S. Electron microscopy for beginners. M.: Мир, 1975, 324p. (Electron-microscopy. Methods and Protocols. Edited by John Kuo. USA, Totowa, New Jersey: Humana Press Inc., 2007, 608 p.85.) 